\title{
O fórum on-line como ferramenta para interação entre alunos e aprendizagem do português como segunda língua
}

\author{
Vanessa Freitas*
}

\begin{abstract}
Resumo
Este artigo apresenta os resultados de um estudo que objetivou investigar as potencialidades dos fóruns on-line num contexto de aprendizagem do Português como Segunda Língua (PL2). Os dados coletados são provenientes de quatro fóruns realizados no ambiente virtual Moodle e consistem em postagens de aprendizes de diferentes nacionalidades matriculados em um curso presencial oferecido por uma universidade privada do Rio de Janeiro em 2019. Entendemos que o fórum virtual é uma ferramenta por meio da qual se pode promover a interação entre colegas e maximizar a aprendizagem fora do ambiente da sala de aula. Os resultados mostraram que os participantes trocaram informações culturais, utilizaram vocabulário adequado, empregaram estruturas linguísticas e estratégias conversacionais estudadas anteriormente e contribuíram para a construção de conhecimentos. No entanto, os fóruns realizados não foram capazes de atrair todos os alunos e aumentar a participação em comparação com as discussões face a face da sala de aula tradicional. Esse resultado pode sugerir que, apesar de instruções claras, ênfase nos objetivos, planejamento e variedade de tópicos, a participação depende da personalidade do aluno e de suas preferências relacionadas à aprendizagem.

Palavras-chave: PL2. Interação. Fórum de discussão on-line.
\end{abstract}

* Pontifícia Universidade Católica do Rio de Janeiro (PUC-Rio). Doutora em Estudos da Linguagem (PUC-Rio), Professora de Português como segunda língua para estrangeiros (Departamento de Letras - PUC-Rio) e do Curso de formação de professores de Português para estrangeiros (CCE - PUC-Rio). ORCID: https://orcid.org/0000-0003-4879-6688. 


\title{
The online forum as a tool for student interaction and Portuguese as second language learning
}

\begin{abstract}
This article presents the results of a study which investigated the potential benefits of online forums in a Portuguese as a second language (PL2) learning context. The data was collected from four forums in Moodle and consists of messages posted by learners from different countries who were attending classes at a private university in Rio de Janeiro in 2019. We believe online forum is a tool whereby one can promote peer interaction and foster learning outside the classroom. Results showed that participants exchanged cultural information, made use of appropriate vocabulary, linguistic structures and conversational strategies previously studied and contributed to knowledge construction. However, the created forums did not attract all the students or increased participation compared to face to face discussions in the traditional classroom. This result suggests that, despite explicit instructions, emphasis on goals, planning and a variety of topics, participation depends on students' personalities and learning preferences.
\end{abstract}

Keywords: PL2. Interaction. Online discussion forum.

Recebido em: 08/03/2021 // Aceito em: 20/04/2021. 


\section{Introdução}

Com cerca de 260 milhões de falantes, o português é hoje a quarta língua mais falada no mundo. Dados obtidos do Novo Atlas da Língua Portuguesa (RETO; MACHADO; ESPERANCA, 2016) mostram que o português já é a quinta língua mais usada na internet e a terceira língua mais usada no Facebook. No cenário acadêmico internacional, programas de ensino de língua portuguesa podem ser encontrados em várias universidades do mundo. No Brasil, universidades federais, estaduais e privadas oferecem cursos de português como disciplinas da graduação ou cursos de extensão para a comunidade externa. E é neste último cenário, relatando minha experiência como professora de Português como Segunda Língua para Estrangeiros (PL2E), ${ }^{1}$ numa universidade privada do Rio de Janeiro, que se insere o presente trabalho.

Quando se trata da aprendizagem de uma nova língua, estando o aprendiz ou não no país em que a língua-alvo é falada, deve-se considerar muito mais do que os aspectos formais da linguagem: é preciso focalizar o desenvolvimento da competência comunicativa do aprendiz. Para tal, estamos sempre buscando alternativas capazes de promover o aprimoramento do processo de ensino-aprendizagem de modo a atendermos as necessidades impostas pelo conjunto de circunstâncias apresentado a nossos alunos. Uma dessas alternativas é a inserção das tecnologias

\footnotetext{
Segundo Meyer (2016), a sigla PLE (Português Língua Estrangeira) não seria adequada em referência ao ensino do português no Brasil, já que o português não é uma língua estrangeira no país. Por sua vez, a sigla PL2 (Português como Segunda Língua), ainda que haja controvérsias quanto ao assunto, tem três vertentes, mas é normalmente usada em referência ao ensino da língua para brasileiros que não têm o português como primeira língua (indígenas e surdos). Desse modo, para falarmos de cidadãos de outros países, falantes de outras línguas que estão no Brasil e "precisam aprender o português para viver em uma sociedade de falantes de português", Meyer sugere a utilização da sigla PL2E. Contudo, o emprego de PL2 no título deste artigo justifica-se pela escolha do termo "aprendizagem" em vez de "ensino", destacando o processo pelo qual os alunos constroem seu conhecimento: seria inadequado dizer "aprendizagem para estrangeiros".
} 
da informação e comunicação (TICs) na educação e a adoção, dentre as inúmeras possibilidades que elas representam, daquelas que melhor se ajustam ao que professores e alunos pretendem alcançar.

Relativamente aos fóruns on-line, tipo de atividade de onde provêm os dados desta pesquisa, estudos anteriores destacaram diferentes aspectos que podem contribuir para o fazer pedagógico e o enriquecimento da aprendizagem. Em seu estudo sobre a construção de conhecimentos linguísticos em fórum on-line, por exemplo, Biondo (2017) procura mostrar que o tema está diretamente ligado às ações de participar, interagir e mediar e às fases da aprendizagem colaborativa (geração de ideias, organização de ideias e convergência intelectual). Analisando postagens provenientes de fóruns on-line de um curso de graduação semipresencial, a autora identifica uma divisão do papel de mediador entre alguns alunos e a professora da turma e a construção de conhecimentos independentemente da mediação docente.

Martins e Araújo (2016) também investigam o fórum de discussão on-line, mas como instrumento avaliativo de aprendizagem, na visão de alunos e tutores de cursos de pósgraduação na modalidade on-line. Concluem que a possibilidade de tutores identificarem as dificuldades dos alunos ao longo do curso e o desenvolvimento da capacidade de aprender a aprender são pontos positivos relacionados à atribuição de uma função avaliativa ao fórum. Como pontos negativos, foram citados o trabalho de mediação do tutor (pouco produtiva ou sem intervenção apropriada), a falta de interação entre os participantes dos fóruns e o design instrucional (qualidade do material e elaboração de questões). 
Já Leffa et al. (2017), em um estudo que aborda as preferências de estudantes de língua inglesa em três atividades distintas do Moodle, apontam que o fórum e a questão dissertativa são preteridos em relação ao quiz. Dentre as justificativas dadas pelos estudantes para a rejeição ao fórum, destacaram-se não querer expor suas próprias ideias e haver uma repetição de ideias. Os autores, contudo, indicam que essa rejeição talvez seja resultado da não compreensão da relação existente entre a atividade fórum e o objetivo principal do curso, que era desenvolver a compreensão de textos em inglês como língua estrangeira. Além disso, a preferência pelo quiz pode ter sido indicada, especialmente por parte de alunos pouco empenhados nos estudos, por sua relativa facilidade.

Nessa breve revisão de literatura, algumas questões sobressaem por sua pertinência ao tema do estudo que originou este artigo: a) a interação entre alunos para a construção de conhecimentos; b) o papel do professor na mediação das atividades realizadas; c) a necessidade de se elaborar uma atividade significativa, com objetivos claros para os estudantes. Tais questões estabelecem um elo com o objetivo do estudo aqui relatado: investigar as potencialidades da atividade fórum no ambiente virtual de aprendizagem (AVA) Moodle em um contexto de aprendizagem do português como segunda língua, com base em uma experiência específica com estudantes estrangeiros, procurando responder às seguintes perguntas:

$\mathrm{O}$ fórum pode, de fato, promover a interação entre alunos e contribuir para o desenvolvimento de diferentes competências ou a atividade pende para um amontoado de mensagens desconexas? 
De que fatores parece depender o bom aproveitamento do fórum?

Foram essas as perguntas que orientaram o delineamento da pesquisa e nortearam a análise dos dados. Antes de explicitar essas etapas, no entanto, veremos alguns conceitos e algumas referências relevantes.

\section{As TICs, os fóruns virtuais e o fazer pedagógico}

O uso das TICs nos processos de ensino-aprendizagem tem impactado profundamente a realidade de muitos estudantes e professores. Com elas, podemos ir além do convencional e desenvolver novas dinâmicas. Em se tratando do ensino formal, aquele que Coombs, Prosser e Manzoor (1973 apud PALANGE, 2017) caracterizam como um sistema educacional hierarquicamente estruturado, o emprego da tecnologia pode enriquecer a aprendizagem, somando ao tradicional,, conhecimentos e informações advindos de experiências de espaços não formais e informais de aprendizagem. Segundo os autores, esses são espaços fora da estrutura do sistema formal em que ocorrem, respectivamente, atividades educacionais organizadas e sistematizadas e uma aprendizagem a partir dos acontecimentos cotidianos e das interações em contextos diversos. Até mesmo a aprendizagem ocorrida nesses espaços é constantemente mediada pela tecnologia. Para Palange (2017), facilitada por dispositivos móveis e pela possibilidade de acesso e conexão, a aprendizagem pode ocorrer a qualquer hora, em qualquer lugar:

A mobilidade, além de criar situações específicas que favorecem a aprendizagem, pode gerar oportunidades 
que despertam a curiosidade e a necessidade de aprender. $\mathrm{O}$ acesso à rede e a possibilidade de conexão permitem a busca de conteúdos interessantes, ou mesmo a interação com diversas pessoas para compartilhar dúvidas e informações para novas aprendizagens. (PALANGE, 2017, p. 90).

No caso específico do ensino-aprendizagem de línguas, as TICs podem contribuir para um maior grau de exposição à língua-alvo, para a diversificação de práticas discursivas e para o desenvolvimento da autonomia do aprendiz. Podemos dizer que, atualmente, apenas a sala de aula física e a adoção de um livro didático já não dão conta das demandas do aprendiz de uma língua. Para Paiva (2005, p. 5), aprender uma língua estrangeira "é um processo que sofre mediações diversas, ocorre em contextos diversificados e não funciona de forma igual com todos os indivíduos". Segundo a autora, de um modo geral, a aprendizagem não pode ser vista como um processo linear: como os seres humanos não são iguais, seus processos de significação e as conexões efetuadas também não podem ser iguais.

Cabe aqui tecer algumas considerações a respeito dos Ambientes Virtuais de Aprendizagem (AVAs) e dos fóruns. Os primeiros são espaços para a promoção da aprendizagem e funcionam, hoje, como verdadeiras salas de aula virtuais com espaço para interação e colaboração. Por sua vez, os fóruns são atividades encontradas nos AVAs e vão muito além de um espaço para avisos. Com planejamento, podem se tornar um espaço de prática e enriquecimento.

Falando especificamente sobre o Moodle, antes utilizado como apoio ao ensino presencial em meu contexto de atuação e, a partir do início da pandemia do coronavírus, como sala virtual em tempo integral, é possível customizá-lo de modo que os 
professores possam inovar em suas práticas pedagógicas por meio de recursos, blocos e atividades, entre as quais temos o fórum, que se destaca por seu caráter assíncrono. Essa característica permite que os participantes interajam sobre determinado assunto por muito tempo, o que vai depender das restrições adicionadas pelo professor. Biondo (2017, p. 42) aponta que a assincronicidade "possibilita a reflexão, o planejamento e a elaboração cuidadosa das postagens, de modo a adequá-las quanto ao conteúdo, estrutura e relevância".

São várias as possibilidades de interação nos fóruns: de acordo com as configurações escolhidas pelo professor, é possível, por exemplo, que um estudante comece uma discussão a qualquer momento, que faça postagens limitadas ou ilimitadas, que só tenha permissão para ler as postagens dos demais colegas após deixarem seu próprio post, que escrevam apenas textos ou que possam incluir arquivos e imagens. É também um meio pelo qual os participantes podem se conhecer melhor, discutir temas que fazem parte do conteúdo programático do curso, com início no ambiente virtual ou como forma de continuar um debate iniciado no ambiente físico da sala de aula, e desenvolver habilidades de leitura e escrita. De acordo com González-Lloret (2019, p. 239), a comunicação mediada por tecnologias digitais estimula a participação ativa do aprendiz e "gera oportunidades para o discurso social e a conversação casual, componentes essenciais do repertório do aprendiz de uma língua".

Assim sendo, incluir as TICs nos processos de ensinoaprendizagem significa repensar e ampliar nosso fazer pedagógico de modo a proporcionar aos alunos oportunidades para o desenvolvimento de novas estratégias de aprendizagem, engajamento e reflexão. Contudo, é preciso planejar 
cuidadosamente as atividades e avaliar constantemente quais fatores parecem determinar sua taxa de sucesso ou insucesso, ajustando-as às particularidades de cada turma para que os recursos tecnológicos não se tornem inócuos.

\section{Interação e participação ativa no processo de aprendizagem}

O termo "interação" pode ser entendido, de acordo com Belloni (2003), como um processo iniciado a partir do encontro de duas ou mais pessoas em um espaço físico ou em um espaço mediado por dispositivos tecnológicos. Para Moore e Kearsley (2007), esse processo se desenvolve a partir das relações estabelecidas entre aluno e conteúdo, entre aluno e professor e entre aluno e aluno. Por meio dos fóruns, essas relações podem se tornar frequentes e possibilitar, como aponta Santos (2003), a construção de conhecimentos, em um processo em que a troca de informações e a participação ativa de cada envolvido, na sua diferença, alimenta a inteligência coletiva. ${ }^{2}$

Com referência à aprendizagem de línguas, Allwright (1984) entende que a interação na sala de aula é fundamental para que os alunos tenham avanços em sua aprendizagem, sendo mesmo um aspecto inescapável das práticas pedagógicas desse espaço, e que professores e alunos são responsáveis pelo que nele acontece. Segundo o autor, mesmo que de forma inconsciente, os alunos contribuem para o gerenciamento de sua própria aprendizagem. Trazendo essas reflexões para a atualidade, pode-se dizer que elas se aplicam a uma sala de aula virtual ou a atividades on-line utilizadas como apoio à sala de aula presencial.

2 Segundo Pierre Lévy (2007, p. 28-29), o termo refere-se a "uma inteligência distribuída por toda a parte, incessantemente valorizada, coordenada em tempo real, que resulta em uma mobilização efetiva das competências", uma inteligência que tem por base e objetivo "o reconhecimento e o enriquecimento mútuo das pessoas". 
No caso específico dos fóruns analisados no âmbito da pesquisa aqui apresentada, interessava saber se a interação entre os alunos, e destes com o professor, por meio dos conteúdos trabalhados e das tarefas realizadas, promoveria oportunidades para o desenvolvimento de diferentes competências (linguística, textual e discursiva) e maior aprendizagem. Em relação a essas diferentes competências, podemos agrupá-las sob o termo "competência comunicativa":

A competência comunicativa é a capacidade do usuário da língua de produzir e compreender textos adequados à produção de efeitos de sentido desejados em situações específicas e concretas de interação comunicativa. Portanto, é a capacidade de utilizar os enunciados da língua em situações concretas de comunicação. A competência comunicativa envolve a competência linguística ou gramatical para produzir frases que sejam vistas não só como pertencentes à língua, mas apropriadas ao que se quer dizer em dada circunstância. Envolve também a competência textual, vista como a capacidade do usuário de, em situações de interação comunicativa, produzir, compreender, transformar e classificar textos que se mostrem adequados à interação comunicativa pretendida, utilizando regularidades e princípios de organização e construção dos textos e do funcionamento textual, já que os textos são a unidade da língua em uso. Evidentemente, incluem-se aqui, na capacidade classificatória, o conhecimento e a capacidade do uso do tipo e do gênero de texto apropriado como instrumento para a interação verbal que está acontecendo. Para além do que já é dado pelas competências linguística e textual, a competência comunicativa acrescenta algo que tem a ver com a competência discursiva, que contextualiza adequadamente o que se diz. Nesse sentido, parece que se pode falar que a competência comunicativa é constituída pelas competências linguística ou gramatical, textual e discursiva. (TRAVAGLIA, 2014). 
Acrescento ao termo o que entendo por competência intercultural: a consciência de que cada cultura tem suas peculiaridades e marcas que formam a identidade daqueles que dela fazem parte, o que envolve ter uma consciência crítica do eu, que permeia as interações com pessoas de origens culturais diferentes.

Considerando que o ensino-aprendizagem de uma língua deve estar voltado para o desenvolvimento da competência comunicativa dos aprendizes, a investigação realizada sobre as potencialidades do fórum nesse processo buscou, nas postagens e mensagens trocadas, elementos que corroborassem que o que foi dito aos colegas e por eles por meio da escrita levouos a refletir sobre a língua em uso, a adequá-la ao contexto e a adquirir conhecimento. Embora os dados não fossem adequados a uma análise detalhada segundo a teoria da "lingualização"3 e as funções do output de Swain (2005), adotou-se aqui a perspectiva segundo a qual "a produção na língua-alvo pode funcionar como um gatilho que força o aprendiz a prestar atenção nos meios de expressão, de modo a transmitir, de forma bem-sucedida, o significado pretendido". (SWAIN, 2006, p. 249 apud PAIVA, 2014, p. 115-116). Segundo Paiva (2014), Swain (2006) entende que a produção na língua-alvo demanda do aprendiz maior esforço cognitivo, aumenta a precisão linguística e, "ao escrever e falar, os aprendizes estão agindo com a linguagem e é na ação comunicativa que percebem o que são ou não são capazes de fazer com a linguagem". (PAIVA, 2014, p. 116)

3 Em inglês, languaging, que se refere ao "processo de produção de sentido e de formação de conhecimento e de experiência por meio da linguagem". (SWAIN, 2006, p. 98). 

aprendizagem do português como segunda língua

\section{Natureza dos dados, sujeitos e procedimentos}

Os dados utilizados no desenvolvimento da pesquisa que motivou este artigo provieram de quatro fóruns realizados no Moodle, no segundo semestre de 2019, numa turma de 16 estudantes estrangeiros de diferentes nacionalidades, aprendizes do português em nível pré-intermediário. No entanto, é importante ressaltar que quatro estudantes não participaram de nenhum fórum. Com idades entre 20 e 35 anos, esses intercambistas estavam matriculados em cursos de graduação e de pós-graduação de uma universidade do Rio de Janeiro, onde atuo como professora, e tinham o português para estrangeiros como disciplina obrigatória ou opcional.

A disciplina era totalmente presencial, mas a equipe de professores de PL2E foi incentivada a desenvolver atividades no Moodle de modo complementar. Optei por trabalhar mais frequentemente com fóruns, no intuito de proporcionar a eles oportunidades extras de interação e aprofundamento nos temas que faziam parte do conteúdo programático, e não com vistas a criar um contexto para a produção de dados de pesquisa. Contudo, a necessidade de aprimorar o trabalho no semestre seguinte, replicando o que deu certo e repensando o que deu errado nessa primeira experiência, motivou a aplicação de um questionário em sala de aula, no final do semestre letivo, a fim de que os alunos avaliassem a utilização do Moodle como um todo. Outra motivação resultante dessa experiência foi iniciar uma investigação acerca das potencialidades da atividade fórum relacionadas à promoção da interação entre alunos e ao desenvolvimento das competências envolvidas na aprendizagem de línguas. Assim, o que se apresenta, neste artigo, é um relato 
de experiência, isto é, a descrição de uma experiência ligada ao processo de ensino-aprendizagem do português como segunda língua mediado pela tecnologia, com público estrangeiro, partindo de uma situação concreta, real.

A investigação propriamente dita teve início no final de novembro de 2019, logo após o fechamento do último fórum, com a exportação dos seguintes dados do ambiente virtual: conteúdo das seções, mensagens postadas nos fóruns e relatórios sobre participantes e suas atividades. O passo seguinte foi criar figuras com informações acerca da participação dos alunos e da professora em cada fórum, das dinâmicas neles empreendidas e do total de visualizações por fórum, a fim de proporcionar uma síntese do que foi encontrado na pesquisa, na seção de resultados. Nessa etapa, por questões de privacidade, os 16 alunos, incluindo os que não participaram de nenhuma dinâmica, foram identificados por uma sigla formada pela letra A, em referência à palavra "aluno", seguida de um número entre 1 e 16, em referência ao número total de alunos da turma. Desse modo, estaria garantido seu anonimato.

A apresentação dos resultados observados e a discussão que sucederam a etapa exposta acima foram acompanhadas de um breve tratamento quantitativo, mas fundamentaram-se essencialmente nos dados de natureza qualitativa, buscando nas postagens analisadas informações que permitissem responder às questões que motivaram a investigação. Para finalizar, aos dados oriundos dos fóruns foram incorporadas informações a respeito das percepções dos estudantes quanto à sua participação nos debates realizados via fórum em comparação aos realizados na sala de aula presencial, extraídas do questionário mencionado no segundo parágrafo desta seção. Embora quatro dos 16 estudantes 
da turma não tivessem participado de nenhum fórum, apenas dois não responderam ao questionário.

A interpretação dos resultados obtidos foi guiada por adequado aporte teórico; no entanto, considerações e impressões de caráter mais subjetivo estão também presentes, uma vez que relatar uma experiência profissional pessoal, envolvendo sujeitos que são seus próprios alunos, torna complexa ao professorpesquisador a tarefa de ater-se integralmente à impessoalidade e à objetividade.

\section{As temáticas dos fóruns}

Para que os leitores deste artigo tenham maior clareza a respeito do trabalho desenvolvido com a turma investigada, será apresentada uma descrição concisa daquilo que foi abordado em cada fórum.

Os dois primeiros fóruns compunham uma mesma seção do Moodle em que foram discutidos os temas da violência contra a mulher e do feminicídio a partir do conto "Venha ver o pôr do sol", de Lygia Fagundes Telles. Como casos de agressão a mulheres registrados em Paris e Londres no início do segundo semestre de 2019 repercutiram em todo o mundo e iniciaram um grande debate, optou-se pelos temas mencionados como forma de engajar alunos em práticas conectadas à realidade experimentada no momento.

O terceiro fórum foi pensado para comentar trabalhos feitos em grupo pelos alunos. Em uma primeira etapa, os alunos registraram, com auxílio de seus smartphones, o espaço físico da cidade e cenas do cotidiano dos cariocas que pudessem enriquecer os conhecimentos de toda a turma sobre a cultura 
carioca. A segunda etapa, realizada em laboratório multimídia, teve como objetivo a elaboração de uma apresentação com base no material produzido. Os trabalhos foram então compartilhados pelo Google Drive e, no ambiente on-line, foi aberto o fórum "Comentando os trabalhos dos colegas", a fim de que pudessem trocar informações sobre suas pesquisas, seus estranhamentos e encantamentos.

Por sua vez, o quarto e último fórum foi aberto para que os alunos conversassem sobre relações sociais e estrutura familiar com base no filme Que horas ela volta?, a que haviam assistido na universidade. Foram selecionados alguns tópicos motivadores, tais como espaços diferentes destinados a patrões e a empregados, falsa polidez, perpetuação de privilégios, subestimação da capacidade de pessoas de classes sociais menos favorecidas, etc., para facilitar as interações.

Essas temáticas foram escolhidas devido à importância de se reservar um lugar para a cultura na sala de aula de línguas, seja ela presencial ou virtual. Segundo Hua (2014, p. 4), quando se trabalha a cultura, desperta-se o interesse do aluno. Contudo, para ele, em referência aos processos de ensino-aprendizagem de línguas, é preciso distinguir "Cultura com C maiúsculo" de "cultura com c minúsculo". Hua (2014, p. 5) explica que a primeira forma se refere a artes, música, literatura, política, etc. Já a segunda diz respeito a padrões comportamentais e modos de vida. Acredito que explorar variados aspectos da cultura referente à língua-alvo e encorajar alunos de diferentes nacionalidades a compartilhar informações sobre suas próprias culturas estimula o desejo de aprender, fornece aos alunos contexto e desenvolve a consciência cultural de todos os envolvidos. 
O fórum on-line como ferramenta para interação entre alunos e aprendizagem do português como segunda língua

\section{Resultados e discussão}

A seguir, será relatado o que foi encontrado na investigação e o que se pode apreender da análise dos conteúdos das postagens e das percepções dos alunos quanto à sua participação.

Para começar, a Figura 1 sintetiza o que indicaram os dados quanto ao número de alunos participantes (de um total de 16) e de postagens feitas em cada fórum:

Figura 1 - Participantes e postagens por fórum

\begin{tabular}{|c|c|c|c|}
\hline Fơrum 1 & Fơrum 2 & Fórum 3 & Fórum 4 \\
\hline $\begin{array}{c}8 \text { alunos } \\
\text { participantes }\end{array}$ & $\begin{array}{c}7 \text { alunos } \\
\text { participantes }\end{array}$ & $\begin{array}{c}7 \text { alunos } \\
\text { participantes }\end{array}$ & $\begin{array}{c}10 \text { alunos } \\
\text { participantes }\end{array}$ \\
\hline $\begin{array}{l}8 \text { postagens } \\
\text { de alunos }\end{array}$ & $\begin{array}{l}8 \text { postagens } \\
\text { de alunos }\end{array}$ & $\begin{array}{l}8 \text { postagens } \\
\text { de alunos }\end{array}$ & $\begin{array}{l}11 \text { postagens } \\
\text { de alunos }\end{array}$ \\
\hline $\begin{array}{l}9 \text { postagens } \\
\text { da professora }\end{array}$ & $\begin{array}{l}4 \text { postagens } \\
\text { da professora }\end{array}$ & $\begin{array}{c}1 \text { postagem da } \\
\text { professora }\end{array}$ & $\begin{array}{l}8 \text { postagens } \\
\text { da professora }\end{array}$ \\
\hline
\end{tabular}

Fonte: Elaborada pela autora

Esse panorama inicial mostra que, em média, houve participação de apenas $50 \%$ da turma em relação ao total de número alunos e que a maioria fez apenas uma postagem sobre cada tópico, sugerindo ter havido um subaproveitamento dos fóruns. O achado é similar ao do estudo de Leffa et al. (2017), que apontou que a maioria dos estudantes envolvidos na investigação se limitou a fazer uma postagem e a comentar a postagem de um colega, cumprindo somente o mínimo exigido para que a tarefa fosse considerada como concluída. 
Em relação ao Fórum 1, a primeira mensagem foi postada pela professora, ${ }^{4}$ que fez aos alunos três perguntas provocadoras. Foi também fornecido um trecho de um artigo sobre feminicídio, seguido do link para acesso ao texto completo, com o intuito de auxiliá-los em sua própria escrita: dessa forma, os alunos teriam contato com vocabulário específico, refletiriam com base nas informações lidas e poderiam aprimorar sua argumentação e enriquecer o debate.

Como ilustra a Figura 2, o primeiro aluno a fazer uma postagem, identificado pela sigla $\mathrm{A} 12$, apenas respondeu às perguntas iniciais, encerrando logo sua participação. Já A9, além de responder às perguntas, citou um caso específico ocorrido em seu país, o que levou a professora a mencionar a Lei Maria da Penha, e A10, aluno de mesma nacionalidade, a interagir diretamente com A9. A10 comentou a postagem do colega, forneceu dados estatísticos, respondeu às perguntas iniciais e citou mais um caso, levando a professora a questionar a interpretação dada pelo aluno a tal caso e a fornecer um link sobre o tema "solidariedade entre mulheres", levantado pelo aluno. Infelizmente, não houve um feedback de A10.

4 Ao descrever as dinâmicas relativas aos fóruns, preferi utilizar "a professora" embora fosse eu mesma a professora da turma e já tivesse relatado muito dessa experiência em primeira pessoa. 
O fórum on-line como ferramenta para interação entre alunos e aprendizagem do português como segunda língua

\section{Figura 2 - Dinâmica do Fórum 1}

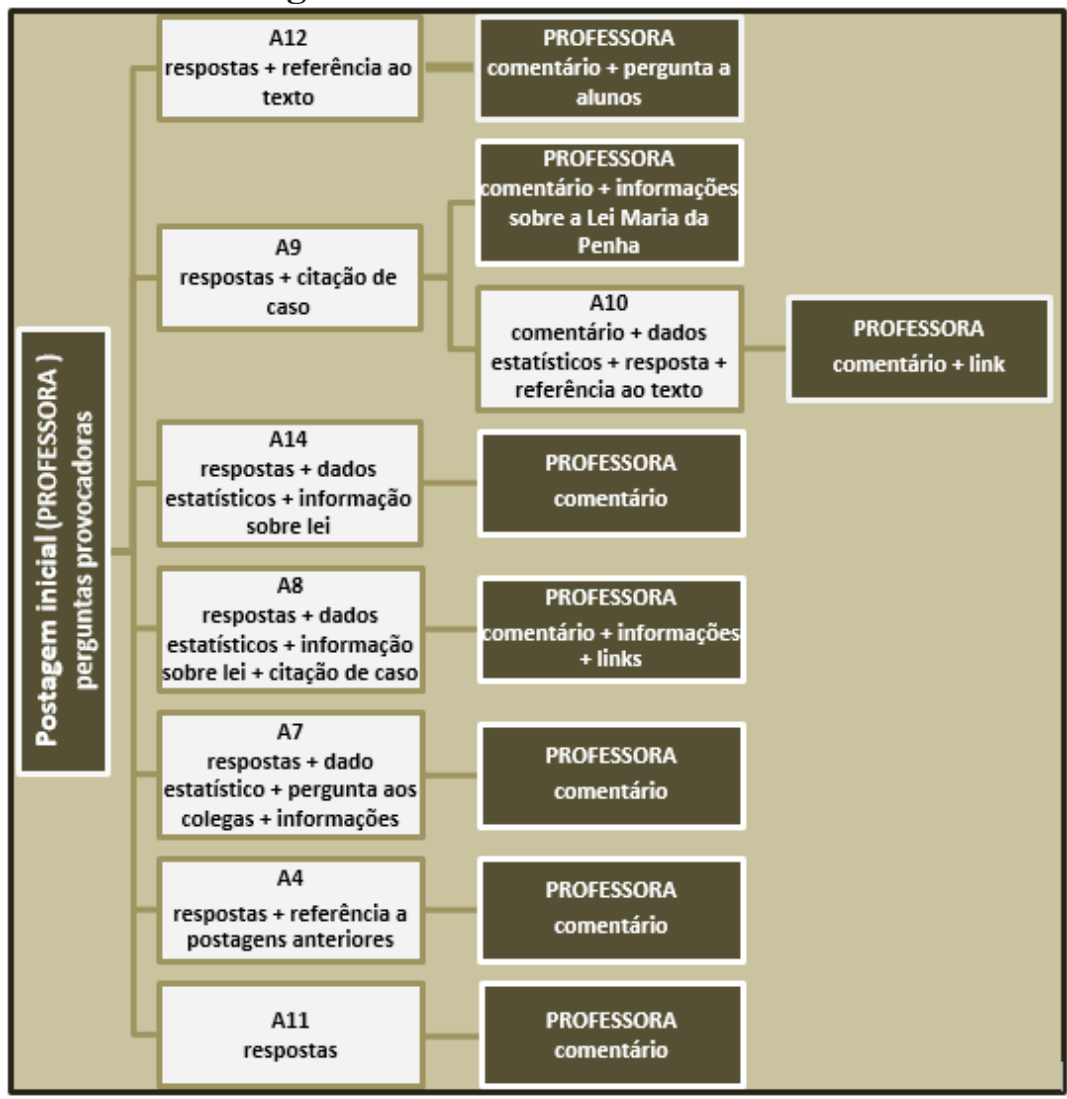

Fonte: Elaborada pela autora

Apesar da baixa participação, um ponto positivo já pode ser percebido: o estímulo ao processo de reflexão. Segundo Palloff e Pratt (2004), citados por Saldanha (2011):

$\mathrm{O}$ fato de apenas pedir aos alunos para responderem às questões de discussão e às mensagens de seus colegas é o suficiente para dar início ao processo de reflexão. Os alunos aprendem que um dos aspectos mais belos da aprendizagem on-line é que eles têm tempo para refletir sobre o material que estudam e sobre as ideias de seus colegas antes de escreverem suas próprias respostas. (PALLOFF; PRATT, 2004, p. 33 apud SALDANHA, 2011, p. 52 ). 
Embora a única mensagem direcionada a um colega particular tenha sido a de A10 para A9, caracterizando a interação de maneira mais visível, percebeu-se que as mensagens dos demais participantes, de algum modo, espelharam-se nas dos colegas, ou seja, não se pode dizer que não houve interação, que o fórum se caracterizou pelo depósito de postagens desconexas. Por exemplo, a professora não orientou os alunos a citar casos específicos, mas, quando A9 decidiu fazê-lo, A8 fez o mesmo, citando um caso em que uma colombiana foi convocada para testemunhar perante o sistema judiciário dias após sua morte. Da mesma forma, uma menção de A9 ao "aspecto judiciário" na França fomentou a menção à Lei Maria da Penha no Brasil pela professora, à Lei Rosa Elvira Celi na Colômbia por A8 e à Lei de Violência de Gênero na Espanha, assim chamada por A14. Os dados estatísticos fornecidos por A10 parecem ter igualmente incentivado A14, A8 e A7 a fazerem uma pesquisa sobre os números da violência em seus países.

Retomando o conceito de interação apresentado no início deste artigo, especialmente por estarmos buscando responder se o tipo de interação observada no fórum permite concebê-lo como atividade capaz de promover a aprendizagem dos estudantes, pode-se discutir aqui se a dinâmica do Fórum 1 é representativa do que chamamos de "interação". Se for levado em conta que o conceito está relacionado à ideia de troca, de influência mútua entre pessoas, é possível afirmar que essa dinâmica não é um conjunto de mensagens desarticuladas, mas um exemplo de interação, de comunicação dialógica: há uma relação de sentidos entre o que foi exposto pelos participantes, visto que a ação de um exerceu influência sobre as ações de outros.

A interação estabelecida entre os participantes também pode ser exemplificada por uma menção direta a mensagens anteriores e por uma estratégia de aproximação por meio de pergunta, em destaque nos trechos abaixo: 
O fórum on-line como ferramenta para interação entre alunos e aprendizagem do português como segunda língua

A4: Todas as informações e opiniões que eu li são um claro exemplo de que o problema da violencia do genero é uma coisa que nenhum país tem podido desertar $100 \%$. Em Espanha como falou A14 o problema continua existente $[\ldots]$

A7: [...] Vocês sabem como é a violência generalizada contra as mulheres em seus países?

O Fórum 2 também abordou o tema da violência contra a mulher, mas focou o feminicídio em uma obra de ficção. Na nova dinâmica ilustrada pela Figura 3, vê-se que, para dar início ao debate com foco no texto literário, a professora postou uma mensagem inicial com perguntas provocadoras, seguindo o mesmo procedimento adotado no Fórum 1. Contudo, pela primeira vez, tem-se um aluno participando com mais de uma postagem.

Figura 3 - Dinâmica do Fórum 2

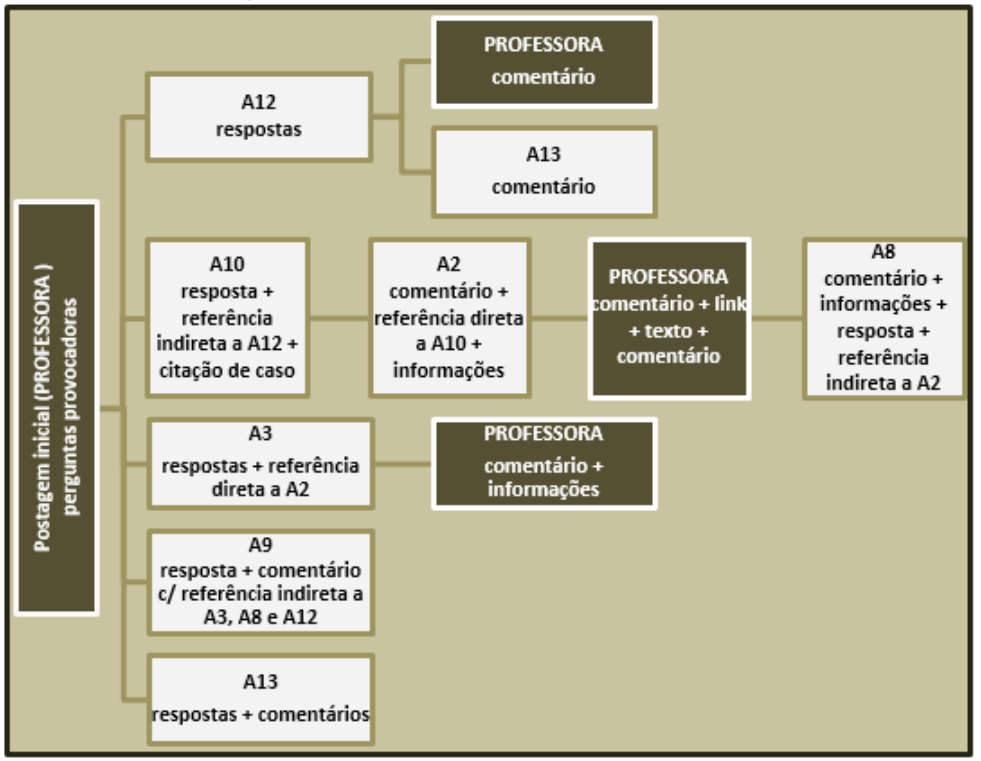

Fonte: Elaborada pela autora.

Inicialmente, A13 comentou a postagem de A2 e concordou com ele a respeito de como o colega havia classificado o 
personagem de nome Ricardo - um psicopata. Mais tarde, além de responder às perguntas provocadoras, fez um comentário que se aproximava do comentário de A2, ainda que não tivesse feito referência ao colega.

Outro ponto observado é que o Fórum 2 não se caracterizou por postagens de caráter individual, com o objetivo de responder às perguntas da professora. A propósito, algumas postagens continham resposta a apenas uma das perguntas ou a nenhuma. Mesmo assim, não houve fuga ao tema principal, o que demonstra interação dos alunos com o conteúdo. Nesse fórum, alguns participantes fizeram referência direta às postagens de colegas, o que corrobora o que já foi dito sobre o indivíduo atuar no processo comunicativo reagindo ao que diz o outro, concordando ou discordando, citando, adicionando, como mostram os trechos abaixo:

A2: Pode ser uma atitude de um psicopata, mas pareceme mais que faz parte do machismo institucionalizado na sociedade. O homem a trancou ela porque ela era sua primeira namorada e porque ele tinha um senso de propriedade sobre ela. Entendo o que A9 quer dizer: o senhor era um psicopata porque planejo tudo, mas em sua lógica machista o que ele fazia era um ato de justiça, pensou: "ela pertence a mim e a mais ninguém". [...]

A3: Eu achei que essa história é um pouco exagerada [...] Como A2 falo em sua resposta, vivemos em um lugar $[\ldots]$

A9: Eu achei também que foi uma história um pouco extrema, que não poderia ser ouvida nas noticias, mas na verdade, não sei se realmente não acontece ou se é que a gente nunca ouve sobre isso porque é nunca descoberto. [...]

Esses mesmos trechos mostram ainda como um fórum pode contribuir para a prática do conteúdo que foi trabalhado presencialmente, de modo espontâneo, não direcionado. Fazem 
parte do programa desse nível de proficiência de português para estrangeiros conteúdos referentes a estruturas interacionais de concordância e discordância, de expressão de opinião e de expressão de certeza e incerteza, tratados a partir de uma perspectiva intercultural e funcional da linguagem. Considerando a cultura brasileira, os alunos entendem que nossas interações tendem a privilegiar a indiretividade e que a elaboração de uma opinião desfavorável ou de uma discordância deve considerar elementos atenuadores.

Há, por exemplo, na fala de A2, indícios de que ele não concorda com a classificação do personagem Ricardo como um psicopata. Contudo, ele não opta por uma discordância direta: os pares "pode ser que/mas" e "entendo/mas" suavizam sua abordagem e denotam uma polidez típica da cultura brasileira. Por sua vez, A3 e A9 usam a expressão "um pouco" para atenuar a carga semântica negativa de "exagerada" e "extrema" ao emitirem suas opiniões. Apesar de pertencerem a culturas diferentes (americana, argentina e francesa), esses três alunos demonstraram habilidades no uso do português brasileiro que contribuem para o desenvolvimento da competência comunicativa de todos os envolvidos.

Por sua vez, o Fórum 3, cuja dinâmica pode ser vista na Figura 4, foi o que menos contou com a participação da professora. Além de os alunos já terem recebido um feedback individual por outro meio, já que o trabalho não foi desenvolvido no AVA, optou-se por dar maior liberdade aos alunos e verificar como a interação ocorreria.

\section{Figura 4 - Dinâmica do Fórum 3}




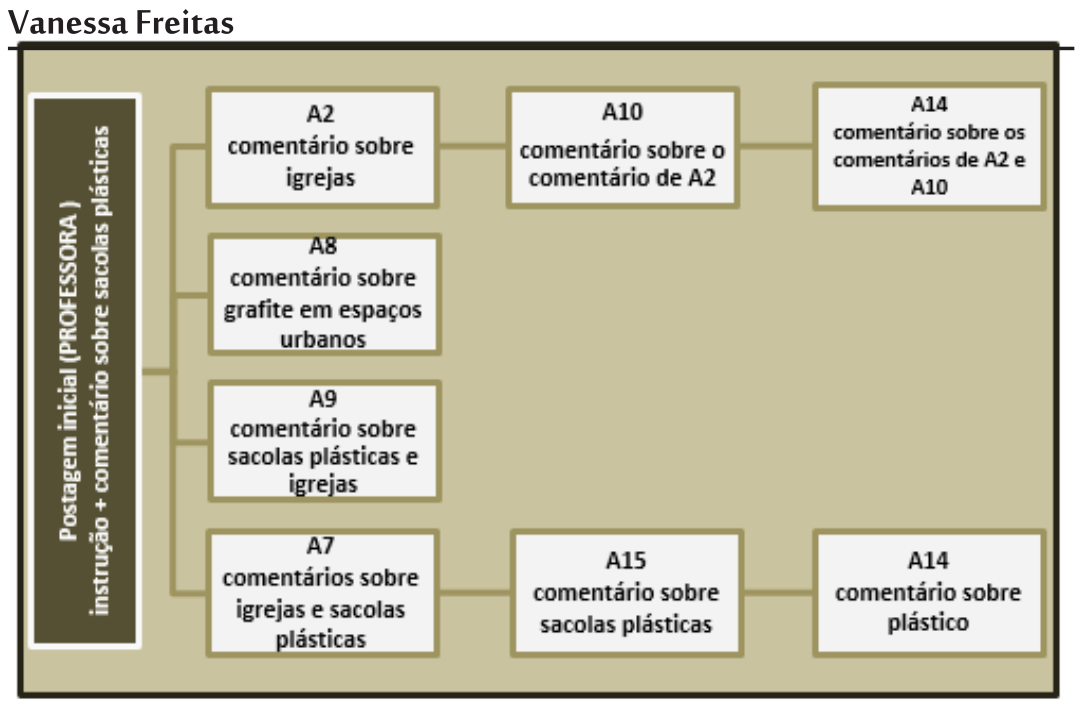

Fonte: Elaborada pela autora.

Faz-se oportuno dar uma pausa, neste momento, para apreciar o papel do professor como mediador no cenário em questão. Peço licença para relatar que fui uma professoraaprendiz nesse processo, tentando ajustar minha participação ao longo do semestre. Considerando os dados da Figura 1, o colega leitor pode avaliá-la como excessiva, mas busquei atuar como incentivadora. Seguindo o que aponta a pesquisa de Saldanha (2011) a respeito do que é essencial para assegurar resultados favoráveis ao processo de ensino-aprendizagem, minha atuação objetivou regular a participação dos alunos, manter a discussão dentro do tema e evitar que o debate se perdesse. É importante não se esquecer de que a interação aluno-professor contribuiu diretamente para a construção do conhecimento à medida que o professor fornecia informações, orientava os alunos e os motivava a entrar em ação.

Ainda acerca do papel do professor no fórum de discussão, Andresen (2009, p. 250-251) aponta ser crucial uma reflexão voltada para o que o professor deve fazer a fim de estimular boas 
discussões e o quanto ele deve intervir, uma vez que um tópico e uma pergunta não garantem que o objetivo será alcançado. O autor entende que as pesquisas que abordam o aspecto da intervenção docente sugerem claramente que o ideal é "afastar-se" e cita, entre outros pesquisadores, Guldberg e Pilkington (2007) e Paloff e Pratt (2004), para os quais a contribuição substancial do professor poderia encurtar a duração e a frequência das discussões, provavelmente por criar uma relação de dependência entre este e os aprendizes.

Esse é um assunto bastante controverso. Conforme destacado anteriormente, na investigação de Martins e Araújo (2016) sobre o fórum de discussão on-line, a maior parte dos pontos negativos mencionados por estudantes refere-se à mediação do professor, considerada pouco frequente, produtiva ou rigorosa em relação às inconsistências de certos alunos. Desse modo, não descartando os resultados de nenhuma pesquisa, talvez a recomendação adequada seja "dosar" em vez de "afastar-se". Buscar o equilíbrio, levando em consideração as características de cada turma, parece ser o caminho.

Voltando à dinâmica ilustrada na Figura 4, a atividade se desenvolveu tendo como ponto de partida uma postagem da professora, que destacou um dos temas escolhidos por um grupo de estudantes para a realização do trabalho sobre aspectos culturais: o uso de sacolas plásticas. Os alunos foram orientados a fazer o mesmo, mas, dos muitos temas trabalhados, apenas três foram abordados. Com exceção da postagem feita por A8 sobre grafite, que não recebeu feedback dos colegas, as demais tiveram como tema a religião, o uso de sacolas plásticas ou ambos.

Como mostra a Figura 4, o comentário de A2 sobre a religiosidade no Brasil e o número de igrejas levou A10 e A14 a 
abordarem o mesmo tema. A mensagem de A10 foi uma resposta direta a $\mathrm{A} 2$, de quem discordou, e não à postagem inicial da professora. Na sequência, A14 respondeu diretamente a A10, discordando dele e concordando com A2, que foi mencionado. Nessa troca, foi interessante notar a menção de A10 ao vocabulário de cunho religioso usado pelos brasileiros, sua percepção quanto a esse uso e o comentário de A14:

A10: Para mim, eu acho que tem muitas igrejas no Brasil, porque tem muitas religoes. Nao é commun na França. [...] Para mim, o Brasil é muito religioso porque tem muitas expressoes na langagem cotidiana: fica com deus, graça a deus...

A14: Eu acho a mesma cosa que A2. Brasil é um país muito religioso, mas tem menos igrejas que a Europa, porque é um país joven. [...] Quanto às expressões mencionadas por a A10, acho que na Espanha temos as mesmas, entao não e uma coisa que chame minha atenção.

Nos trechos acima, vê-se um exemplo claro de que o fórum pode ser um espaço de reflexão e aprendizagem a partir de diferentes opiniões e de troca de conhecimentos, com possibilidade de livre expressão, sem hierarquização de papéis. Vários alunos mencionaram seus países, estabeleceram comparações com o Brasil e contribuíram para o desenvolvimento da consciência cultural de cada um dos participantes. No entanto, muitos não têm clareza do quão importante é sua participação para a aprendizagem do grupo, e essa é uma questão que deve ser pontuada a fim de incentivá-los a incrementar suas participações em quantidade e qualidade. Conforme aponta Allwright (1984, p. 156), não se pode ver o professor apenas como professor, ou o aluno apenas como aluno, pois ambos gerenciam a aprendizagem, e é gerenciando a interação que se consegue gerenciar a aprendizagem. 
Por último, apresentarei considerações sobre o quarto fórum, "As relações sociais em Que horas ela volta?", criado com a orientação de que os participantes conversassem sobre o filme, destacando suas impressões e estranhamentos.

A fim de que os participantes não focalizassem apenas um ou dois aspectos ligados às relações sociais no Brasil evidenciados no filme, como fizeram em relação ao fórum anterior, explicitou-se que cada um deveria escolher dois tópicos (dos seis dados) para comentar. Adicionalmente, foram encorajados a complementar observações feitas pelos colegas, para que o fórum não se caracterizasse pela inserção de respostas isoladas à tarefa proposta. No entanto, as orientações não surtiram o efeito desejado. Encerrado o fórum, pôde-se notar que, seguindo o exemplo de A7, os outros participantes escolheram dois tópicos e fizeram suas observações. Com exceção de A8, que selecionou os mesmos tópicos de A14, complementando o que este havia exposto, não se percebeu o mesmo tipo de interação ocorrido nos fóruns anteriores. A Figura 6 abaixo sintetiza como se deu a nova dinâmica: 
Figura 6 - Dinâmica do Fórum 4

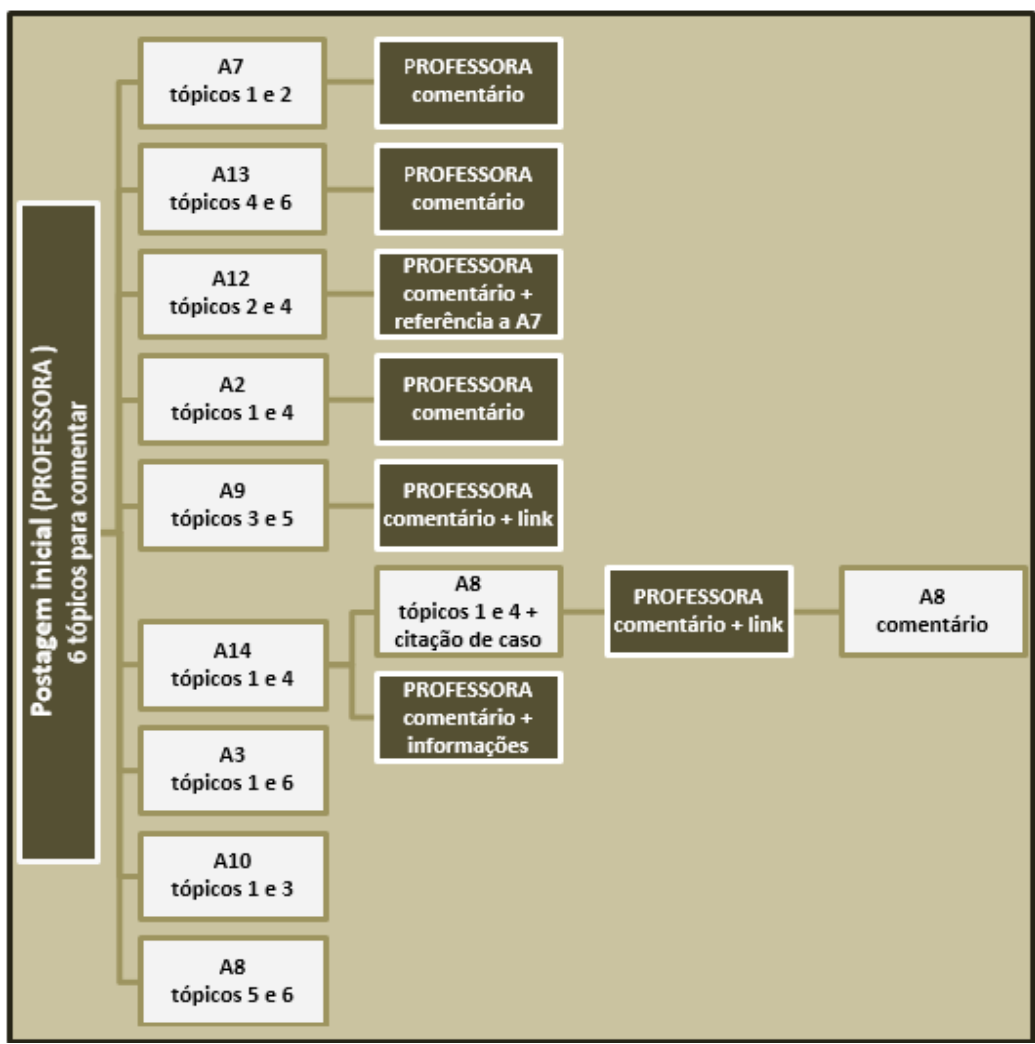

Fonte: Elaborada pela autora.

Embora as postagens mostrassem que houve uma excelente compreensão do filme e que os participantes foram capazes de expressar suas opiniões brilhantemente, por meio de uma escrita coerente e coesa (considerando seu nível de português), não houve menção direta ou indireta a outros colegas ou a informações dadas por eles. As participações da professora, com inclusão de links e incentivos para que os alunos não limitassem sua participação a uma postagem, também não surtiram efeito visível. 
O fórum on-line como ferramenta para interação entre alunos e aprendizagem do português como segunda língua

Não se pode dizer, contudo, que a atividade não foi produtiva, especialmente quando voltamos nosso olhar para o número de visualizações do fórum: foram 102 visualizações. Isso justifica o uso do adjetivo "visível" na última frase do parágrafo anterior. Conforme mostra a Figura 7, o número de visualizações em cada fórum, informação obtida no próprio AVA, superou o número de postagens:

Figura 7 - Visualizações nos fóruns

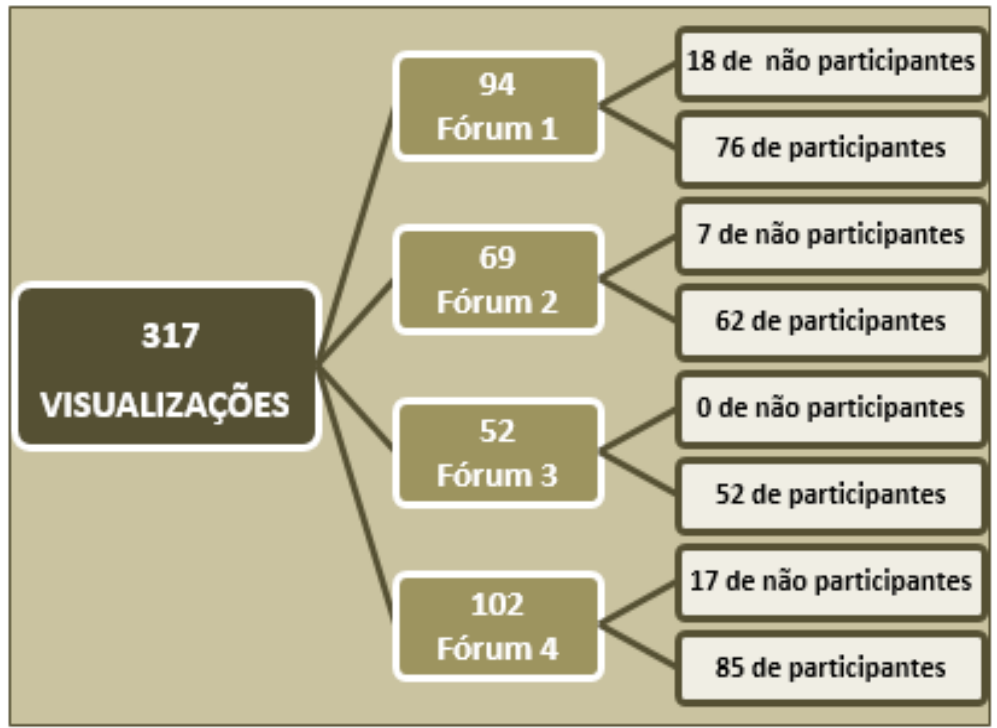

Fonte: Elaborada pela autora.

Esses dados podem indicar que o interesse dos alunos pelos temas talvez seja maior do que se supunha e nos fazem questionar por que uma participação mais ativa e intensa não ocorreu. Por que apenas visualizar e não participar ou se aprofundar nos debates? 
Para responder a essa pergunta, é importante considerar que, independentemente dos esforços do professor, do interesse dos demais colegas e da relevância dos temas propostos para o debate, os alunos têm diferentes personalidades, ritmos, motivações e preferências relacionadas ao estilo de aprender. Não se pode negar que esses fatores exercem certa influência na atitude dos alunos perante os tipos de atividade propostos pelo professor. Talvez precisemos reconhecer que todos os alunos participando ativamente e intensamente de todos os tipos de atividades é idealizar um cenário que não admite a existência de alunos que possuem outras preferências e que nem sempre vão se encaixar no que é proposto. Alguns alunos podem até sentir certo constrangimento em expor suas ideias. Leffa et al. (2017) verificaram que o desconforto em publicar algo que outros vão ler foi justamente um dos fatores apontados em seu estudo para justificar certa rejeição ao fórum. O medo da exposição também foi citado em estudo publicado por Hammond (2000) sobre a comunicação em fóruns on-line.

Voltando às visualizações, se estas não foram uma "olhadinha" apenas, é possível considerar que, mesmo sem a interação aluno-aluno ou aluno-professor, a leitura atenta das postagens dos participantes e dos textos fornecidos via link tenha contribuído para promover a reflexão e ativar o senso crítico, atuando como uma espécie de estimulador cognitivo. Isso os torna seres passivos? A leitura não mobiliza estruturas mentais e possibilita novas aprendizagens? Para Moraes (2002, p. 25), a leitura pode ser um "valioso instrumento para aprendizagem de novos conhecimentos", capaz de oferecer ao leitor "novas perspectivas ou opiniões sobre determinados aspectos, aproximando-o da cultura (ou de múltiplas culturas) e é uma contribuição essencial para a cultura do próprio leitor”. 
E como os próprios alunos avaliaram sua participação?

Ao encerrarmos o semestre, 14 alunos responderam às perguntas de um questionário sobre o Moodle no processo de ensino-aprendizagem, entre elas, se tiveram maior participação nos debates realizados no ambiente on-line ou nos presenciais, com solicitação de justificativa.

Em geral, os alunos tiveram a impressão de terem participado mais dos debates presenciais, o que pude confirmar ao comparar, como professora da turma, minhas observações e avaliações referentes à participação dos alunos nas tarefas realizadas presencialmente e informações exportadas do AVA. Apenas dois afirmaram terem tido maior participação no ambiente on-line. Um desses alunos justificou sua resposta afirmando que, no ambiente virtual, tinha mais tempo para "achar" o que podia falar, mas que normalmente preferia falar face to face. Para o outro, a facilidade proporcionada pelo ambiente e o fator tempo foram os diferenciais. Quanto aos outros 12 alunos, as justificativas dadas (não necessariamente uma por aluno) para a não participação ou menor participação no ambiente virtual foram: a) ser mais fácil falar do que escrever (1); b) preferir falar (1); c) preferir uma forma de interação direta, que para o aluno é o debate presencial (1); d) ter mais tempo em sala de aula presencial (1); e) não dispor de muito tempo para o debate virtual (7); f) não haver muitas "conversações" no ambiente virtual (1); g) já falar muito no presencial (1); h) ser mais fácil durante a aula presencial (1).

Como cada turma tem uma composição diferente, cada aluno tem uma personalidade e preferências individuais, talvez tivéssemos resultados diversos na investigação de um contexto diferente, ou seja, como este estudo relata uma experiência específica, realizada em um curto período de tempo, não é possível fazer generalizações, mas apenas produzir conhecimentos que possam contribuir para a reflexão e a prática docentes. 
Em suma, quanto às potencialidades do fórum virtual como meio de promoção da interação entre alunos e maximização da aprendizagem fora do ambiente da sala de aula, os resultados da investigação indicam que, por meio desse recurso, é possível: explorar a construção colaborativa de conhecimentos; fornecer aos alunos oportunidades para interagir na línguaalvo; proporcionar aos alunos tempo para pensar sobre a língua e aprofundar-se em temas variados; fomentar a consciência intercultural; aprimorar a competência comunicativa na línguaalvo.

As conclusões acima expostas podem ser corroboradas pelo que constataram alguns dos pesquisadores citados ao longo deste texto. Por exemplo, Biondo (2017) procura mostrar que a ideia de um processo colaborativo na construção de conhecimentos tem relação direta com as ações de participar, interagir e mediar: são essas ações realizadas na atividade fórum que permitem analisála como "prática colaborativa de construção de conhecimentos". (BIONDO, 2017, p. 45). Embora os fóruns analisados neste artigo tenham mostrado que as ações de participar, interagir e mediar por parte dos alunos não tenham sido substanciais em termos quantitativos, o mesmo não se pode dizer da qualidade das discussões. É particularmente difícil avaliar a qualidade das contribuições de cada indivíduo, mas se adotarmos como um dos parâmetros a capacidade de uma postagem influenciar as postagens dos demais colegas, talvez possamos tecer algumas considerações de modo menos subjetivo.

Por sua vez, a capacidade de proporcionar aos alunos momentos de interação na língua-alvo, quando o professor lhes fornece uma atividade bem elaborada, com tema que seja de seu interesse e com objetivos claros, acaba sendo uma característica 
inerente ao fórum. Obviamente, como diz o ditado, uma andorinha só não faz verão: é preciso um esforço coletivo, um engajamento de todos, ou da maioria. Uma vez que todos esses fatores estão em cena, criam-se oportunidades de diálogo que devem fazer parte do repertório de quem está aprendendo uma língua (GONZÁLEZ-LLORET, 2019). A qualidade desses diálogos é também maximizada pelo fator tempo: as postagens dos alunos da turma considerada, nesta pesquisa, mostram que exercitar a produção, na língua-alvo, com a possibilidade de refletir sobre o melhor meio de se expressar, produz textos com uma linguagem mais elaborada, o que pode facilitar a compreensão dos colegas e tornar a interação mais bem-sucedida. Estabelecem-se aí os meios para o desenvolvimento da competência comunicativa objetivada no processo de ensino-aprendizagem de línguas.

\section{Considerações finais}

A pesquisa que originou este artigo contemplou fundamentalmente a possibilidade de o fórum virtual poder se configurar como um espaço de interação entre aprendizes estrangeiros do português como segunda língua e de incremento da aprendizagem. Os dados coletados nos mostraram que, embora parte dos 16 alunos da turma tenha participado e interagido entre si, atendo-se aos temas propostos e compartilhando preciosas informações culturais, os debates no ambiente virtual não tiveram a adesão esperada.

As dinâmicas dos fóruns tiveram configurações variadas, normalmente com apenas uma postagem por participante, mas o conteúdo dessas postagens e o grande número de visualizações nos levaram a questionar se a participação dos alunos se deu 
como se fossem meros expectadores. Esse processo também teve a participação da professora da turma, autora deste artigo, como mediadora da aprendizagem. Sua atuação teve como objetivo auxiliar os alunos em suas interações, fazendo conexões com as informações e ideias lançadas por cada um, sugerindo links para maior aprofundamento sobre os temas e motivando-os a participar.

De modo geral, a experiência com o fórum virtual como apoio ao ensino presencial teve um saldo positivo. $\mathrm{O}$ fórum tem potencial para promover interação, desenvolver a autonomia dos estudantes e as competências de que precisam para se comunicar na língua-alvo. Entretanto, pode não atender a todos os gostos.

Como pontos positivos da experiência relatada, destacamse: 1) a produção cuidadosa dos textos das mensagens, com uso de vocabulário apropriado e estruturas bem formadas; 2) a troca de informações sobre diferentes culturas e o reconhecimento de que há diferentes realidades e formas de ver o mundo; 3) o emprego de estratégias de interação para estabelecer uma comunicação produtiva. Já os pontos negativos mais salientes são: 1) a ausência ou baixa participação de alguns alunos; 2) a falta de informações precisas sobre a percepção dos alunos quanto ao seu desempenho, à mediação do professor, aos temas abordados e ao que deve ser aprimorado. Essas informações poderiam ter sido obtidas por meio de um questionário mais detalhado.

Por fim, é importante ressaltar que foram identificadas algumas limitações da pesquisa. Como a carga horária do curso era de 90 horas presenciais e os alunos tinham uma carga de estudos intensa na universidade, o trabalho com fóruns, por se dar fora da sala de aula, precisou ser limitado, ou seja, não foi 
O fórum on-line como ferramenta para interação entre alunos e aprendizagem do português como segunda língua

possível desenvolver atividades via fórum com maior frequência. Estudos mais longitudinais fornecem maior quantidade de dados e permitem análises mais detalhadas quanto à sua natureza e à sua complexidade.

\section{Referências}

ALLWRIGHT, Richard L. The importance of interaction in classroom language learning. Applied Linguistics, [s. l.], v. 5, n. 2, p. 156-171, 1984.

ANDRESEN, Martin. Asynchronous discussion forums: success factors, outcomes, assessments, and limitations. Journal of Educational Technology \& Society, [s. l.], v. 12, n. 1, p. 249257, 2009.

BELLONI, Maria Luiza. Educação a distância. 3.ed. Campinas: Autores Associados, 2003.

BIONDO, Fabiana. Construir conhecimentos linguísticos em fórum on-line: uma prática colaborativa. Veredas on-line, [s. l.], v. 21, n. 1, p. 40-59, 2017. Disponível em: <https://www.ufjf.br/ revistaveredas/files /2017/09/ARTIGO-3.pdf>. Acesso em: 26 abr. 2020.

GONZÁLEZ-LLORET, Marta. Technology for task-based language teaching. In: CHAPELLE, Carol, A.; SAURO, Shannon. (Ed.). The handbook of technology and second language teaching and learning. Oxford, UK: Wiley Blackwell, 2019. p. 234-247.

GULDBERG, K.; PILKINGTON, R.M. Tutor roles in facilitating reflection on practice through online discussion. Educational Technology \& Society, 10(1), p. 61-72, 2007.

HAMMOND, Michael. Communication within on-line forums: the opportunities, the constraints and the value of a communicative approach. Computers and education, [s. l.], $\mathrm{n}$. 
35, p. 251-262, 2000.

HUA, Zhu. Exploring intercultural communication: language in action. London and New York: Routledge, 2014.

LEFFA, Vilson. J. et al. Preferência dos estudantes na aprendizagem de línguas em três atividades do Moodle. RBLA, Belo Horizonte, v. 17, n. 1, p. 113-136, 2017.

LÉVY, Pierre. A inteligência coletiva: por uma antropologia do ciberespaço. 5.ed. São Paulo: Edições Loyola, 2007.

MARTINS, Alexandra da Costa Souza; ARAÚJO, Lucicleide de Sousa Alves. $\mathrm{O}$ fórum de discussão como instrumento avaliativo da aprendizagem. Informática na Educação: teoria \& prática, [s. l.], v. 19, n. 2, p. 106-122, jun./set. 2016.

MEYER, Rosa Marina de Brito. Estudos em PL2E no Brasil: trajetórias e tendências. In: RIBEIRO, Alexandre do Amaral (org.). Ensino de português do Brasil para estrangeiros: internacionalização, contextos e práticas. Rio de Janeiro: Epublik, 2016. p. 29-46.

MOORE, Michael; KEARSLEY, Greg. Educação à distância: uma visão integrada. São Paulo: Tomson Learning, 2007.

MORAES, Maria José Ferreira de. O uso de estratégias cognitivas na produção textual de alunos do ensino médio. 2002. 165 f. Dissertação (Mestrado em Linguística) - Programa de Pós-Graduação em Letras, Universidade Federal de Pernambuco, Recife, 2002.

PAIVA, Vera Lúcia Menezes de Oliveira e. Modelo fractal de aquisição de línguas. In: BRUNO, Fátima Cabral. Ensino e aprendizagem de línguas estrangeiras: reflexão e prática. São Carlos: Clara Luz, 2005. p. 23-36.

PAIVA, Vera Lúcia Menezes de Oliveira e. Aquisição de segunda língua. São Paulo: Parábola Editorial, 2014.

PALANGE, Ivete. Espaços educativos e suas mobilidades. São Paulo: Editora Senac São Paulo, 2017. (Série Universitária). 

aprendizagem do português como segunda língua

PALLOFF, Rena M.; PRATT, Keith. O aluno virtual: um guia para se trabalhar com estudantes on-line. Porto Alegre: Artmed, 2004.

RETO, Luís Antero; MACHADO, Fernando Luís; ESPERANCA, José Paulo. Novo Atlas da Língua Portuguesa. Lisboa: Imprensa Nacional - Casa da Moeda, 2016.

SALDANHA, Camila Teixeira. Interação nos fóruns de discussão: uma análise linguística. 2011. 202 f. Dissertação (Mestrado em Educação) - Centro de Ciências da Educação, Universidade Federal de Santa Catarina, Florianópolis, 2011.

SANTOS, Edméa Oliveira. Ambientes virtuais de aprendizagem: por autorias livres, plurais e gratuitas. Revista Faeba, [s. l.], v. 12, n. 18, 2003.

SWAIN, Merrill. The Output Hypothesis: Theory and Research. In: HINKEL, E. (org.) Handbook of Research in Second Language Teaching and Learning. Mahwah: Lawrence Erlbaum Associates, 2005. p. 471-483.

SWAIN, Merrill. Languaging, agency and collaboration in advanced second language learning. In: BYRNES, H. (Ed.). Advanced language learning: the contributions of Halliday and Vygotsky. London, England: Continuum, 2006. p. 95-108.

TRAVAGLIA, Luiz Carlos. Competência comunicativa. In: GLOSSÁRIO Ceale: termos de alfabetização, leitura e escrita para educadores. Belo Horizonte: UFMG/Faculdade de Educação, 2014. Disponível em: <http://www.ceale.fae. ufmg.br/app/webroot/glossarioceale/verbetes/compe tenciacomunicativa >. Acesso em: 30 abr. 2020. 